\title{
El declive estructural de lo público y la dialéctica desarrollo/subdesarrollo: génesis y manifestaciones de la crisis de Estado en México
}

\section{The structural decline of the public and the dialectic development/ underdevelopment: genesis and manifestations of the State crisis in Mexico}

doi: http://dx.doi.org/10.32870/espiral.v26i74.7037

Isaac Enríquez Pérez

\section{Resumen}

El presente artículo analiza las dimensiones simbólico-institucionales de la génesis y perpetuación del subdesarrollo, con énfasis en el declive de la vida pública y la crisis de Estado en México. Para ello, son explorados las distintas fuerzas, factores y poderes fácticos que -desde afuera y desde adentro, desde arriba y desde abajo- gravitan, trastocan y reconfiguran los entramados institucionales, las funciones del Estado y las decisiones públicas ante la transformación de la soberanía nacional. El objetivo es comprender la manera en que se entrelazan el declive de lo público, las transformaciones del Estado y la proliferación de actores y fuerzas que desafían su poder, le disputan la hegemonía e inciden en el diseño de la agenda pública, al extremo de que las élites políticas pierden capacidad para la articulación, cohesión y regulación de la sociedad.

Palabras clave: dialéctica desarrollo/ subdesarrollo, crisis de Estado, planeación y decisiones públicas, espacios globales para la toma de decisiones, soberanía nacional.

\section{Abstract}

This article analyzes the symbolic-institutional dimensions of the genesis and perpetuation of underdevelopment, with emphasis on the decline of public life and the state crisis in Mexico. For that, the different forces, factors and factual powers that -from the outside and from within, from above and from below- gravitate, upset and reconfigure the institutional frameworks, the functions of the state and public decisions facing the transformation of national sovereignty are explored. The objective is to understand how there is a relation between the decline of the public, the transformations of the state and the proliferation of actors and forces that challenge its power, dispute the hegemony, and affect the design of the public agenda, to the extreme that political elites lose capacity for the articulation, cohesion and regulation of society.

Keywords: Dialectic development/underdevelopment, state crisis, planning and public decisions, global spaces for decision making, National sovereignty.

- Profesor-Investigador en Universidad Nacional Autónoma de México (UNAM), México. ORCID: http://orcid.org/0000-0003-I36I-538I_isaacep@unam.mx

Fecha de recepción: 20 de febrero de 2018. Fecha de aceptación:03 de septiembre de 2018 . 
Introducción'

Si la sociedad contemporánea está marcada por la crisis -tornándose esta en algo estructural y sistémico, más no transitorio, y, por tanto, en un perpetuo fenómeno que trastoca la vida social-y por la transformación de las instituciones gestadas a la par de la consolidación del Estado moderno europeo, las sociedades subdesarrolladas no escapan a esa tendencia, que se reproduce con el agrietamiento finisecular de los cimientos del capitalismo y del contrato social que le dio forma, proyección y legitimidad desde el siglo XVIII, esto a partir del arraigo de la institución jurídica de la soberanía y de las ideologías de la libertad y la democracia.

Particularmente, el declive de la vida pública, suscitado a finales del siglo Xx tras la erosión de la ideología liberal y el agotamiento del Estado de bienestar y del Estado desarrollista en el sur del mundo, significó el desmonte y reconfiguración de aquellas instituciones y organizaciones que le dieron sentido al sector público y relativa cohesión a las sociedades y a sus proyectos de desarrollo nacional.

Esta erosión y remoción de los entramados institucionales que caracterizaron a muchas sociedades nacionales adquirió, hacia las décadas de los ochenta y noventa del siglo pasado, rasgos radicales y desestructuradores en las economías subdesarrolladas, acercándolas en no pocos casos a una crisis de Estado, que tiene como una de sus manifestaciones la proliferación de actores socioeconómicos y políticos, externos e internos, legales e ilegales, que le disputan al Estado la hegemonía y el control sobre la modelación y estructuración de la sociedad.

I. Este trabajo fue realizado como parte de las actividades de investigación en la Unidad Académica en Estudios del Desarrollo de la Universidad Autónoma de Zacatecas, y financiado por el Consejo Nacional de Ciencia y Tecnología (Conacyt) a través de su Programa de Estancias Posdoctorales Vinculadas al Fortalecimiento de la Calidad del Posgrado Nacional. 
Señalado este antecedente, cabe preguntarse: ¿por qué se experimenta un declive de lo público en una nación subdesarrollada como México? ¿Cuáles son las causas y las distintas manifestaciones y facetas de esta crisis de lo público? ¿Cuáles son los fundamentos y la génesis de la crisis de Estado suscitada en México durante los primeros lustros del siglo XXI? ¿Cómo incide esta crisis y fragilidad de los entramados institucionales en la dialéctica desarrollo/ subdesarrollo de la referida nación? ¿Cómo se manifiesta esta crisis estructural de lo público en la toma de decisiones en materia de planeación y diseño de políticas públicas, particularmente ante la influencia ejercida por los organismos internacionales y los espacios globales para la toma de decisiones? ¿Es la fragilidad institucional de las naciones subdesarrolladas un incentivo que debilita a los Estados en sus funciones de planeación y de diseño y adopción de la política de desarrollo? Estas interrogantes permiten abordar la necesidad de comprender, explicar e interpretar la lógica de la crisis de Estado y el sentido que asume este fenómeno histórico en la perpetuación del subdesarrollo de las estructuras económicas y sociales mexicanas.

Orientado por estos cuestionamientos, el presente artículo tiene como objetivo estudiar el sentido que adopta el declive del espacio público en México y su entrelazamiento con la multifacética crisis de Estado que tiende a debilitar los entramados institucionales y sus funciones reguladoras y cohesionadoras de la vida social. Esta crisis abre espacios para que diversas fuerzas y agentes socioeconómicos y políticos - desde afuera y desde adentro, desde arriba y desde abajo-incidan directamente en la definición de los problemas públicos y en la configuración de la agenda pública.

A grandes rasgos, se argumenta en el presente material que la crisis de Estado se inscribe en un fenómeno más amplio, relacionado con la subsunción y volatilización de la praxis política ante el predominio de diversos mecanismos 
de poder (o contrapoder) y de agentes que lo configuran y ejercen desde diferentes espacios, incluso a costa de la eliminación de los límites entre lo público y lo privado.

Este argumento puede ayudar a comprender la lógica que reproduce y profundiza el subdesarrollo en una nación como México, y sitúa la crisis de lo público en el contexto histórico más amplio de la crisis del capitalismo como modo de producción y proceso (des)civilizatorio que suprimió los mecanismos de cohesión social estatales ante la entronización de la utopía del mercado autorregulado.

\section{La fragmentación y transformación del Estado y la emergencia de múltiples fuerzas y agentes en la configuración de los mecanismos de poder}

En medio de la necesidad de construir y preservar la estabilidad política y la paz social, el siglo XX mexicano se caracterizó por la presencia de un Estado centralizado, corporativo, omniabarcador y autoritario (González Casanova, 1975; Paz, 1978 y 1979; Cosío Villegas, 1972 y 1974; López Villafañe, 1986) que, a través de reglas no escritas y mecanismos metaconstitucionales estandarizados por el presidencialismo y el partido cuasioficial, mantuvo relativamente disciplinada y bajo control a la constelación de agentes e intereses facciosos y de grupo.

Sin embargo, la actividad y el intervencionismo estatal no redundaron en el fortalecimiento y consolidación del espacio público y de los entramados institucionales, en buena medida porque la relación entre el Estado y la sociedad fue mediada por prácticas corporativo-clientelares y por otras relacionadas con el prebendalismo, el ejercicio patrimonialista del poder político y los cargos públicos, la centralización de las decisiones públicas, la discrecionalidad en el manejo del gasto público, la opacidad, la corrupción, la impunidad, la negociación selectiva y arbitraria de la 
legalidad, la cooptación, entre otras que se complementaron con la pasividad y la limitada o nula cultura cívico-política de amplios sectores de la población. Todo esto condujo a las élites políticas mexicanas a apropiarse de la vida pública desde el aparato de Estado.

Este proceso histórico de implantación deformada del espíritu cívico, que tiene implícitos el socavamiento y erosión de la vida pública, se exacerbó hacia los últimos lustros del siglo Xx con el advenimiento de la crisis del Estado desarrollista y con el agotamiento de la noción misma de desarrollo, que, heredera del ideal moderno de progreso, había articulado y legitimado desde finales de los años cuarenta el discurso de las élites políticas, los mecanismos de intervención del sector público, los proyectos de nación en múltiples sociedades subdesarrolladas e, incluso, las directrices de los organismos internacionales en sus pretensiones de vertebrar una diplomacia del desarrollo.

Este punto de inflexión significó el debilitamiento de las instituciones estatales -especialmente de su gestión directa del proceso económico- ante la crisis fiscal del sector público y su subsecuente privatización, en el contexto de la desindustrialización y de un intenso proceso de extranjerización de las decisiones económicas y de inserción subordinada en y dependiente de la economía mundial.

A escala planetaria, algunos estudiosos de la sociedad contemporánea reconocen un dislocamiento o escisión entre el poder y la praxis política. Esta situación se traduce, en cierta medida, en una incapacidad del Estado para ejercer la toma de decisiones públicas (Bauman y Bordoni, 2016), y se evidencia en la postración del Estado tras ser reducido a una macroestructura para la gestión, regulación y facilitación de los flujos globales, con capacidad acotada (o nula, en el caso de las naciones subdesarrolladas) para modelarlos o contenerlos y para satisfacer las necesidades de la población a través de las redes de seguridad social. 
De este modo, los llamados espacios globales para la toma de decisiones se desarraigan de los espacios locales y nacionales, y sus poderes fácticos tienden a transnacionalizarse y a escapar del control fiscal, jurídico y político de un Estado-nación subsumido y volatilizado por emergentes estructuras que cuestionan y socavan -desde afuera y desde adentro, desde arriba y desde abajo- su legitimidad y los alcances de su jurisdicción. Estos poderes fácticos centralizan decisiones que anteriormente eran potestad exclusiva de los Estados, controlan amplias porciones de los territorios e, incluso, disputan el monopolio legítimo de la violencia y de la procuración de justicia, lo que disemina su predominio en lo local y nacional y en amplios espectros de la vida social.

Particularmente, México, más que erigirse en un Estado fallido (failed state), se manifiesta como un Estado fragmentado ante la proliferación de diversos poderes fácticos que tienden a debilitarlo en sus potestades, decisiones, alcances y legitimidad. Por si fuera poco, el Estado mexicano muestra una limitada capacidad para unir y articular a los variados actores y agentes socioeconómicos y políticos locales, nacionales o transnacionales; públicos o privados; legales o ilegales.

Esta fragmentación del Estado mexicano, cimentada en la pérdida del control territorial y en la dispersión o diseminación del poder, se presentó de manera paralela a la erosión y suplantación del Estado desarrollista y de su política y estrategia de industrialización como articuladora del proyecto de nación y del mercado interno en condiciones de aparente paz social, por lo que el Estado mexicano redefinió sus funciones esenciales a partir de 1985, hasta sustraerse y vaciarse de contenido respecto a sus instrumentos de intervención en los procesos de construcción de mercados y de distribución de la riqueza. 
El declive estructural de lo público y la dialéctica desarrollo/subdesarrollo: génesis y manifestaciones de la crisis de Estado en México

Esto último se manifiesta en un sector público con perfil acotado y retraído, en la debilidad o selectividad de sus intervenciones, y en su incapacidad o ausencia respecto a las responsabilidades y funciones que le otorgaron identidad, viabilidad y sentido histórico. Así, desde 1985, de ser un agente económico que desplegó funciones estratégicas de rector, planificador, promotor, banquero, inversionista, propietario de medios de producción ${ }^{2}$ y regulador en la construcción de mercados y en los arreglos y entramados político-institucionales en torno a las formas de distribución de la riqueza, el Estado mexicano, en tanto macroestructura institucional, transitó a funciones de convocante, publicista o ejecutor de marketing de los territorios locales y regionales, proveedor de entornos institucionales en aras de apuntalar la dimensión macroeconómica, y gestor y facilitador de la inversión privada (Enríquez Pérez, 2016a).

Este desmantelamiento del poder económico directo del Estado mexicano, y de sus resortes corporativo-clientelares que lo habían reforzado y le habían brindado legitimidad y control, significó, en un escenario ascendente de crisis institucional, la expansión del poder del empresariado privado y la transnacionalización de las decisiones económicas al unísono con la fragmentación y dispersión territorial de la cadena de valor marcada por los sistemas internacionales de producción integrada y los encadenamientos mercantiles mundiales.

El dislocamiento del Estado mexicano respecto a la estructuración y regulación del espacio público y su transmutación a una macroestructura institucional socavada, acotada, retraída y hasta ausente en amplios ámbitos de la vida social tuvieron como correlato la proliferación de fuerzas, actores y agentes socioeconómicos y políticos que inciden

2. Lo que significa que se desempeñó como productor y proveedor de insumos, bienes y servicios a través de las empresas paraestatales. 
en la toma de decisiones públicas y en la configuración de la sociedad. Sin embargo, estos actores, fuerzas y agentes, al sustraerse del férreo control autoritario propio del sistema político mexicano presidencialista y unipartidista, contribuyen, de múltiples formas, a subvertir, suplantar y depredar los entramados institucionales que le otorgan sentido al espacio público.

A este omnipresente Estado territorial, generalizado en múltiples latitudes del mundo y mediado por las relaciones corporativas y clientelares, se le otorgó, a lo largo de la segunda mitad del siglo xx, credibilidad y legitimidad como garante en la resolución de los problemas sociales. Sin embargo, con el cambio en sus funciones esenciales, la fe y la confianza en el Estado se eclipsaron y desvanecieron, en un contexto de incertidumbre y de degradación de la cohesión social que entronizó al mercado y a la iniciativa privada como los nuevos mantras para la prosperidad y la eficiencia. $^{3}$

Esos nuevos poderes fácticos, contenidos en fuerzas, actores y agentes de diverso tipo, alcanzaron, en el contexto de las transformaciones finiseculares del Estado mexicano, una importante autonomía y protagonizaron una ruptura de las reglas no escritas que habían regido la disciplina y la relativa cohesión del sistema político, vigente desde 1929 y particularmente a partir de 1946.

Por si fuera poco, dichos poderes fácticos, conforme se debilitó el poder económico y político del Estado, tendieron a depredar, socavar y desafiar los alcances de las instituciones estatales, lo cual se ha evidenciado con el desmedido poder que han adquirido desde la década de los noventa los grandes grupos empresariales nacionales y extranjeros, las Iglesias, los medios de comunicación masiva, el crimen organizado y otros actores con poder territorial, de tal modo

\section{4}


que el espacio público ha sido trastocado por estos intereses creados y por la impotencia e ineficacia del aparato de Estado para detonar y encauzar el crecimiento económico, la distribución de la riqueza y el bienestar social, la provisión de seguridad pública y la preservación de la integridad física de los ciudadanos, y la procuración e impartición de la justicia. ${ }^{4}$

El panorama planteado se complementa con la depredación de lo público ejercida por una élite tecnocrática que torna borrosas las fronteras entre los intereses del Estado y los privados (Salas-Porras, 2014), y la conformación, incluso, de relaciones y prácticas sociales más allá de las fronteras nacionales tras la interacción en espacios globales y comunidades epistémicas en los que se delibera sobre la agenda pública y las estrategias de política.

A esa diseminación del poder más allá de los entramados institucionales del Estado mexicano, y la consecuente entronización de actores y agentes socioeconómicos y políticos dotados de poderes y contrapoderes fácticos, contribuyó la transformación de la soberanía y el desdibujamiento del proyecto de nación trazado en la constitución de 1917. La redefinición de potestades del Estado respecto a la articulación de la sociedad, el territorio y las fuerzas sociales se agravó con las transiciones experimentadas en sus funciones y estrategias de intervención, así como con el desvanecimiento y alteración de las prácticas corporativas y clientelares que, en su época, resultaron funcionales para el ejercicio del poder político y para desplegar y profundizar el proceso de acumulación de capital.

Aunado a lo anterior, las decisiones públicas no son acatadas ni legitimadas unánimemente por los poderes fácticos y los grupos de presión. Más aún, se observa que 
la vida pública y sus instituciones son asediadas y subordinadas por estas fuerzas sociales y sus irrestrictos intereses facciosos en amplios territorios del país, incentivados por la permisividad, la impunidad, la colusión y el desdén por la ley y lo público.

Por si fuera poco, el eclipsamiento, socavamiento y depredación de las instituciones estatales y del espacio público en formaciones sociales y estructuras económicas subdesarrolladas ${ }^{5}$ incentiva la gestación, expansión y fortalecimiento de esos poderes y contrapoderes fácticos que, amparados por las élites políticas y las reglas no escritas, acceden y disponen de vastos recursos económicos y financieros, políticos, simbólicos, mediáticos e, incluso, armados y paramilitares, los cuales utilizan para desplegar dominación y violencia sobre individuos, conciencias, comunidades, territorios, riquezas, recursos naturales estratégicos, presupuestos públicos, etc.

De esta forma, los (contra)poderes cuestionan y desafían la hegemonía del aparato de Estado, sus cimientos republicanos, el monopolio legítimo de la violencia física, el control del territorio, su autoridad y sus posibilidades de ejercer autonomía en la toma de decisiones y el diseño de las políticas públicas.

Sumado a lo anterior, se destaca que, por ejemplo, con el crimen organizado y otros poderes ilegales enraizados en el territorio, se erigen mecanismos de (contra)poder capaces de desafiar y desestabilizar los arreglos políticos, la convivencia social y la institucionalidad formal, así como de configurar una parainstitucionalidad estatal que se traslapa y trasciende los entramados institucionales legalmente establecidos.

5. Estas estructuras económicas son agraviadas, además, por prácticas y relaciones sociales y políticas antidemocráticas, antipopulares, verticales, autoritarias, asimétricas y excluyentes, que navegan en un mar de débil cultura ciudadana y frágiles instituciones.

\section{6}


No menos importante es el tejido social en las regiones y las redes globales, que apuntala la economía subterránea y criminal al traslaparse con la economía legal y el sistema bancario-financiero y al valerse, ante la intensificación de los procesos de globalización, de la porosidad de las fronteras que ofrecen la apertura comercial y las redes de irrestrictos flujos masivos de personas, capitales, insumos, bienes, servicios, conocimiento, tecnología, información, contactos y privilegios.

\section{La soberanía nacional y el diseño de la agenda pública ante el asedio de los poderes y contrapoderes fácticos}

Si un Estado subdesarrollado como el mexicano es trastocado y transformado en sus cimientos fundacionales y en el sentido histórico de sus funciones esenciales por los poderes y contrapoderes que pretenden incidir en la estructuración de la sociedad, cabe argumentar que la agenda pública no queda al margen de ello. Es decir, si la soberanía nacional se redefine a la luz de fuerzas y factores exógenos que escapan de las potestades y el control absoluto del Estado, la definición de los problemas públicos y la configuración de las estrategias de intervención para solucionarlos también adquieren forma a partir de la incidencia de dichos factores y fuerzas (ver: Figura 1).

Esto ocurre de múltiples maneras: el proceso económico, si bien nunca fue controlado plenamente por los Estados -y menos por el Estado de corte keynesiano-, ante la fragmentación y dispersión territorial de la cadena de valor el capital, se desarraiga de los espacios locales y nacionales y deambula entre múltiples territorios estratégicamente integrados y coordinados hasta conformar redes transplanetarias que apuntalan la acumulación y apropiación de la riqueza. 
Figura 1. Factores, circunstancias, fuerzas y (contra)poderes fácticos que inciden en la modelación de las decisiones públicas $y$ en las funciones del Estado mexicano

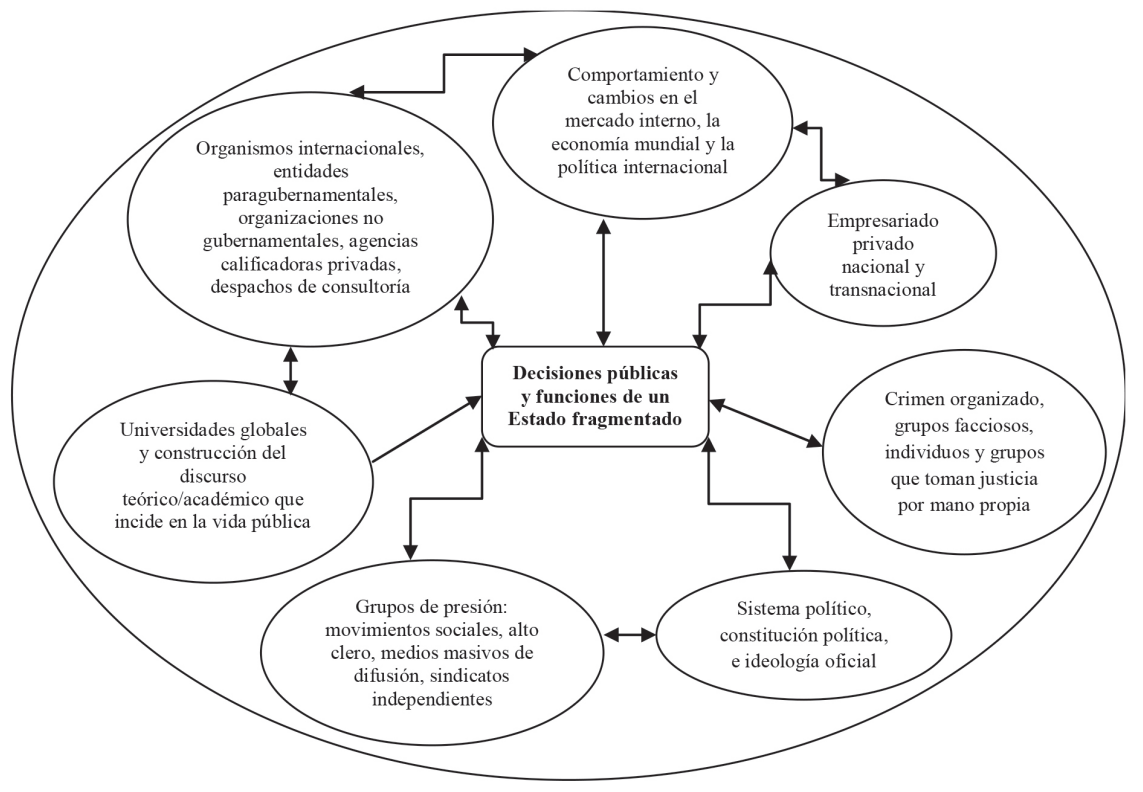

Fuente: elaboración propia.

Esta tendencia, presente en las últimas tres décadas, impone fricciones y grilletes a los Estados con el fin no de sepultar su soberanía económica, sino de que diseñen y adopten estrategias de política económica dotadas de principios y criterios nacionalistas. En cuanto a la praxis política, la sincronización asimétrica de espacios globales para la toma de decisiones perfila la coordinación, armonización, estandarización y homogeneización de directrices de política pública que inciden en las escalas locales y nacionales, y si bien eso se configura con la anuencia de los aparatos de Estado, se crea una densidad institucional gestionada por élites y tecnocracias transnacionales, desarraigadas de los intereses nacionales y cuyas regulaciones adquieren vida propia. 
El declive estructural de lo público y la dialéctica desarrollo/subdesarrollo: génesis y manifestaciones de la crisis de Estado en México

Respecto a la dimensión simbólico-cultural, la diversidad e interculturalidad acompañan la intensificación de multidireccionales flujos informacionales, simbólicos, de personas y estilos de vida que no son controlados plenamente por los Estados y que redefinen el sentir, comportamiento y composición de las poblaciones nativas. La misma comunicación supraterritorial apoyada en la atmósfera del Internet y el ciberespacio se torna irrestricta en este proceso de intercambio de símbolos, imágenes y sonidos que materialmente desbordan el control de los Estados y generan nuevos desafíos y problemáticas sociales con importantes repercusiones en los espacios locales.

Más aún, la llamada sociedad del riesgo global (Beck, 1998 y 2002) impone cuantiosos desafíos a los Estados a medida que se magnifican fenómenos como el cambio climático, el calentamiento global, las enfermedades contagiosas, los contaminantes, las catástrofes naturales, las crisis económico-financieras y la violencia criminal, que se transnacionaliza en redes.

Cabe puntualizar que la globalización no es una tendencia tersa, y mucho menos armoniosa y equilibrada, sino que entraña y está expuesta a contradicciones, a las asimetrías propias del capitalismo y a la correlación de fuerzas que impera en la economía mundial y la política internacional. El escenario se vuelve complejo a medida que la misma globalización torna difusas las fuentes del poder y abre el camino para tejer una constelación de redes entrelazadas por múltiples actores hegemónicos posicionados de manera diferenciada.

En ese contexto, ¿hasta qué punto resulta válido hablar de Estados soberanos? Es una pregunta cuya respuesta no puede plantearse sólo a partir de la noción de soberanía entendida como institución jurídica, sino que también está en función de la coordenada geopolítica y geoeconómica en la que se posiciona una nación como parte del sistema 
mundial, así como de la solidez o fragilidad de los entramados institucionales que sostienen la vida pública en las sociedades nacionales.

Si bien la economía mundial y la política internacional necesitan de los Estados en su comportamiento y para regir su estructura y dinámica, desde la década de los noventa abundan los argumentos que evidencian la emergencia de un nuevo orden mundial donde el Estado pierde protagonismo y su soberanía es cuestionada por múltiples factores y fuerzas (Albrow, 1996; Scholte, 1996 y 2005; Strange, 1996; Ohmae, 1995; Drucker, 1994; Camilleri y Falk, 1992; Julius, 1997; Messner, 1997; Ianni, 1996, 1998 y 1999), los cuales, en una especie de relación orgánica, se imponen (Enríquez Pérez, 2016b):

- Desde afuera: globalización, mercado global, procesos de integración económica y regionalización, apertura comercial, regímenes internacionales, organismos internacionales, redes globales de toma de decisiones, comunidades epistémicas y élites transnacionales;

- Desde adentro: crimen organizado y actores y agentes sociales que controlan amplias porciones del territorio nacional y que disputan el monopolio legítimo de la violencia;

- Desde arriba: medios de comunicación masiva, empresariado privado, inversionistas institucionales y especuladores financieros, las Iglesias y las diferentes teologías, líderes sindicales, élites políticas corruptas, rentistas y patrimonialistas que se apropian de lo público; $\mathrm{y}$

- Desde abajo: grupos de presión, paramilitares, movimientos guerrilleros, organizaciones de base y comunidades que toman justicia por propia mano.

Todo esto sucede en un cambiante equilibrio de fuerzas en el que la soberanía se torna difusa y compartida, y donde las decisiones públicas se ciñen a las mismas circunstancias. 
El declive estructural de lo público y la dialéctica desarrollo/subdesarrollo: génesis y manifestaciones de la crisis de Estado en México

En estas circunstancias, la pregunta sobre la existencia real de Estados soberanos es una cuestión teórica y política de gran calado que no es ocioso intentar responder, y que resulta aún más relevante si se asume que las sociedades emanadas de la modernidad Europea, y la dinámica misma de las relaciones internacionales, se estructuraron en torno a la figura del Estado-nación, y que a la par de ello el pensamiento político y las ciencias sociales gestadas en el siglo XIX tuvieron como principal referente de sus reflexiones y teorizaciones a la sociedad nacional regida bajo el imperativo jurídico-político de la soberanía.

Aunque el Estado-nación no llega a su crepúsculo ni las sociedades prescinden de sus funciones y alcances, lo que se evidencia es una reconfiguración de sus fundamentos y de sus instrumentos de intervención y regulación de la vida social. Si bien se suscita una retracción o un repliegue del Estado tras menguarse su autonomía, ${ }^{6}$ múltiples ámbitos y funciones estatales se fortalecen y se tornan más incisivos en la vida de los individuos y las sociedades; al final de cuentas, los seres humanos nacen, hacen su vida y ejercen su ciudadanía en los márgenes del Estado-nación.

Por ello, más que la desaparición del Estado, lo que se presenta es una fase de transformaciones profundas en sus articulaciones, potestades y campos de decisión e intervención. En esos cambios y rupturas, el papel desempeñado por la intensificación de las relaciones interestatales, transnacionales y supranacionales es fundamental, pues, sin lugar a dudas, transforma y tiende a desvanecer el poder, la autoridad y las potestades del Estado en un escenario de transcontinentalización y de interacciones e interconexiones transplanetarias y supraterritoriales que agudizan la incertidumbre en el seno de un sistema mundial dotado de

6. Sobre este argumento, en su versión exacerbada que enfatiza la extinción del Estado ante el predominio del mercado y la muerte de la política, véanse: Czempiel (1989), Naisbitt (1994), Guehénno (1995) y Ohmae (1995). 
soberanías compartidas y moldeado por las transiciones en el patrón de acumulación y en los arreglos sociales propios de la distribución de la riqueza. Todo ello es matizado por el trepidante cambio tecnológico experimentado en las últimas décadas del siglo XX, que desborda los alcances de los Estados al tornarse más porosas las fronteras por los irrestrictos flujos estimulados por esas innovaciones.

Entre estas profundas transformaciones del Estado, destacan las relacionadas con el proceso de toma de decisiones y el diseño de la agenda pública. Es precisamente esa diseminación del poder y su desanclaje respecto a la política lo que redefine en buena medida el sentido de las decisiones públicas y del proceso de planeación. La noción de soberanía compartida ayuda, por un lado, a comprender la manera en que se articulan los poderes fácticos que gravitan desde arriba y desde afuera y que trastocan los cimientos del orden internacional westfaliano.

La emergencia de problemas globales que desbordan las fronteras nacionales amerita altas dosis de cooperación internacional y la provisión de bienes públicos globales (Kaul, Grunberg, y Stern, 1999), esto ante la impotencia e ineficacia de los Estados respecto a brindar respuestas y soluciones unilaterales a los desafíos contemporáneos. Este imperativo propicia la configuración de estructuras de poder y de toma de decisiones protagonizadas por organismos interestatales o supranacionales y organizaciones no gubernamentales entrelazadas en redes y en flujos que restan, pero que no eliminan, autonomía a las entidades estatales.

La tendencia apunta a una relativa retracción de la autoridad del Estado y a una configuración del poder en la que convergen múltiples fuentes, fuerzas y agentes que se distancian de la praxis política. Esto es catalizado por la distinción entre lo público y lo privado y por la expansión 
El declive estructural de lo público y la dialéctica desarrollo/subdesarrollo: génesis y manifestaciones de la crisis de Estado en México

del mecanismo de mercado a través de la empresa e iniciativa privadas.

Sin que exista una oposición o una subordinación entre el mercado y el Estado, ${ }^{7}$ el sector público (aunque no controle plenamente las posibilidades para esbozar una estrategia autónoma de desarrollo) se erige históricamente como una pieza fundamental en la creación del engranaje propio de la acumulación de capital y de la lógica de la economía global, esto mediante el tejido de entramados institucionales y regulaciones que legitiman, estabilizan, vigilan y le otorgan orden, estructura y sentido al capitalismo.

Es decir, pese a esa acusada retracción, el Estado es la principal macroestructura institucional (una relación social con poder coercitivo, simbólico y administrativo, y no una cosa o un sujeto unitario con voluntad propia, en palabras de Bob Jessop -2017-) que modela, moldea y contribuye a la construcción de los mercados, al tiempo que, en mayor o menor medida según la coordenada geopolítica y geoeconómica, controla relativamente las leyes sociales de la distribución de la riqueza y al conjunto de los agentes que inciden en el proceso económico y la vida social.

En sí, aunque el control sobre los asuntos nacionales no le es exclusivo, el Estado continúa siendo la forma de organización social y la arena política por excelencia en la cual se disputan y concilian los intereses de las sociedades y desde donde se esboza la acción colectiva para el diseño de las posibles soluciones respecto a los problemas públicos y los conflictos propios de la redistribución de la riqueza.

Es justo esta estrecha y recíproca relación entre política y economía, entre Estado y mercado, lo que define la dialéctica desarrollo/subdesarrollo y sus posibilidades de

7. Más bien, cabe la posibilidad de hablar de una codependencia o de una relación dialéctica en la que se habilitan, constriñen y controlan mutuamente. Es posible rastrear esta noción en pensadores como Karl Polanyi (1992). 
bienestar (o malestar) social en el concierto del capitalismo y su sistema mundial.

A grandes rasgos, un Estado que tenga como prioridad el fomento del desarrollo necesita, a decir de Evans (1995), una autonomía arraigada o enraizada (embedded autonomy) que permita, por una parte, que el Estado no sea un instrumento de los poderes fácticos y, por otra, que se imbrique o enraíce en el conjunto de la sociedad y logre cierto grado de cohesión social para controlar su proceso económico. Es de destacar que en naciones relativamente autónomas, esta imbricación con la sociedad no es sinónimo de fragmentación o desbordamiento de las instituciones estatales ante la proliferación de poderes y contrapoderes fácticos.

La misma expansión y operatividad de los poderes y contrapoderes fácticos se suscita gracias a esos entramados institucionales construidos desde la praxis política y las decisiones públicas. Por acción, omisión o colusión desde los agentes del Estado, el mercado y demás actores y organizaciones que desafían el poder estatal se configuran, adquieren sentido y son guiados por las reglas del juego (formales, informales o no escritas) estipuladas desde la jurisdicción de esos mismos agentes.

Aquí cabe matizar que esta gravitación desde adentro y desde abajo posiciona en un Estado como el mexicano a múltiples actores y agentes que le disputan la hegemonía en la sociedad y el territorio, luego de que se han roto las reglas no escritas que fundamentaron las raíces del sistema político posrevolucionario, cuyo control constreñía la acción social de dichos agentes.

Empresarios privados y especuladores financieros, alto clero, medios de comunicación masiva, movimientos sociales, sindicatos, organizaciones criminales, entre otros, fueron controlados, si bien no plenamente, desde el aparato de Estado a través del régimen de economía mixta, las estrategias proteccionistas y las políticas de represión 
financiera, el laicismo, la cooptación de líderes sociales, la censura y el control de contenidos mediáticos, los pactos, y el reparto del territorio con el crimen organizado. Rotas esas reglas no escritas, estos poderes fácticos adquirieron autonomía y se desprendieron del control del Estado, al grado de disputarle hoy la hegemonía en su base material (gestión directa del proceso económico, dominio del territorio, provisión de servicios sociales, etc.).

En condiciones de subdesarrollo y de inserción asimétrica y subordinada en la economía mundial y la política internacional, las transformaciones de los Estados periféricos destacan más. La globalización, entendida como la intensificación de las interacciones e interconexiones transplanetarias y supraterritoriales, y como un proceso de transcontinentalización de las relaciones sociales, tiende a manifestarse de manera desigual al interior de las sociedades y en el plano internacional.

De esta manera, la intensidad de la reespacialización y la reterritorialización de la vida social, sus alcances geográficos y las manifestaciones de sus impactos en las escalas local y nacional son asimétricas, y ello no es la excepción en la incidencia que estos factores exógenos ejercen sobre el perfil, funciones y cambios del Estado. Y si bien los Estados modulan, a través de las políticas públicas, los alcances, la orientación y el sentido que adopta el proceso de globalización, la planeación, las decisiones públicas y los márgenes de su soberanía son influidos por fenómenos, fuerzas y factores de corte transfronterizo que se entrelazan, intergeneran y materializan con los procesos propios de los espacios locales y nacionales que también gravitan en la configuración del poder.

Particularmente, en un escenario de diseminación y proliferación de los poderes y contrapoderes fácticos, las potestades, funciones y decisiones públicas del Estado relacionadas con la dialéctica desarrollo/subdesarrollo 
transforman su naturaleza y adquieren un sentido diferente para incorporar en sus criterios y directrices la gravitación ejercida por factores, circunstancias y agentes tanto exógenos como endógenos que -sin estar exentos de tensiones y conflictos- marcan su impronta y condicionamientos, preñado esto de las cosmovisiones, concepciones, intereses y proyectos de los actores hegemónicos y de aquellos que moldean o disputan dicha hegemonía.

Incluso en el contexto marcado por la expansión e integración global del capitalismo, más que caer en la argucia ideológica de más mercado y menos Estado, lo que amerita la profundización del mecanismo de mercado en la economía mundial y al interior de las sociedades nacionales es más Estado con fuerte e integra capacidad reguladora, procedimental, de supervisión y gestión. Esto se observa en el mayor requerimiento de entramados institucionales para regular las cuantiosas operaciones comerciales, financieras, monetarias y de servicios, así como los flujos de capital, bienes, información, símbolos y personas, al interior de las fronteras y entre ellas (Altvater y Mahnkopf, 1997 y 2002).

Al mismo tiempo, el Estado provee una importante cantidad de bienes y servicios públicos sin los cuales los mercados no funcionan con eficiencia ni contribuyen a corregir sus desequilibrios e inequidades. Piénsese en el papel de la política social y los servicios públicos de educación y salud, las funciones policiaco-militares, la provisión de infraestructura básica (especialmente de comunicaciones y transportes), la emisión de dinero, entre otras.

A la fábrica global y a los sistemas internacionales de producción integrada los acompaña una estructura jurídica global diseminada y sincronizada a lo largo y ancho del planeta, y dotada de normas, procedimientos y mecanismos para la solución de controversias, diseñados por distintos actores y agentes públicos, sociales y privados: órganos de los Estados, organismos internacionales, entidades para- 
El declive estructural de lo público y la dialéctica desarrollo/subdesarrollo: génesis y manifestaciones de la crisis de Estado en México

gubernamentales, organizaciones no gubernamentales, agencias calificadoras privadas, agencias de consultoría y think tanks.

No menos importante en el ámbito de la institucionalidad global que moldea los contornos del capitalismo y en la cual los Estados desempeñan funciones complejas, son las redes de políticas públicas globales (Reinicke, 1999) que orientan sus esfuerzos y posibles soluciones hacia aquellos ámbitos obviados por el mecanismo del mercado y los agentes públicos con la finalidad de complementarlos de cara a las insuficiencias regulatorias de estos. En todo ello, la interconectividad de los diferentes actores y poderes desempeña un papel crucial en aras de privilegiar la armonización, estandarización, homogeneización y coordinación de las políticas públicas a escala planetaria.

En las sociedades contemporáneas, los problemas públicos tienen resortes globales que, en última instancia, se expresan y materializan en los espacios locales y nacionales, y precisamente por las insuficiencias de estos se pronuncian y agravan los impactos de aquellos. Ante esto, las funciones y recursos de los Estados, especialmente de aquellos débiles y subdesarrollados, no son suficientes para enfrentar los alcances de los problemas públicos y los efectos negativos profundizados en sus territorios.

Más aún, el Estado, en tanto macroestructura institucional, se imbrica en redes globales de toma de decisiones que, si bien no lo subsumen del todo, trastocan y transforman sus fundamentos al intergenerarse con otros actores y agentes socioeconómicos y políticos, y al erigirlo como una entidad polifacética, difuminada, fragmentada en su poder y avocada a compartir su soberanía con otros poderes que no precisamente emanan de sus confines (ver: Figura 1).

Por ello, las decisiones públicas son modeladas y matizadas por la coordinación de fuerzas y organizaciones públicas y privadas, gubernamentales, paragubernamentales y no 
gubernamentales ante las cuales el Estado lleva la voz cantante, o bien donde, a decir de Jessop (2002), el Estado se torna en un primus inter pares. Se trata, pues, de redes transestatales que se perfilan a partir de la gravitación ejercida por esos poderes fácticos locales y transnacionales.

De esto se desprende que el problema de la soberanía nacional atraviesa por la tendencia del Estado a desvanecer su autoridad en un escenario de múltiples poderes que le restan sus alcances de controlar, en el contexto de la expansión e integración global del capitalismo, todos los fenómenos suscitados en los márgenes de sus fronteras, así como las posibilidades de que vertebre proyectos de desarrollo nacional.

De esta forma, el Estado subdesarrollado, caracterizado en no pocos casos por su desdén respecto al imperio de la ley y por su debilidad e ineficacia administrativo-institucional, y no por apegarse al tipo ideal del Estado moderno europeo, se encuentra expuesto, en mayor o menor medida, a: 1) el carácter desestructurante de la economía mundial; 2) los desequilibrios del mercado; 3) el desarraigo territorial de los sistemas internacionales de producción integrada -motivado a su vez por el cada vez más irrestricto movimiento de capitales-, de los encadenamientos mercantiles intra- e interregionales y de las redes financieras globales; y 4) el asedio de los intereses de grupo que condicionan la estructura y comportamiento de las instituciones estatales. La soberanía en el mundo subdesarrollado no desaparece ante un Estado sitiado, pero se redefine radicalmente de cara a la influencia de estos poderes fácticos en las decisiones públicas.

En su sentido tradicional, la soberanía remite al derecho y a la posibilidad de autodeterminación de los pueblos y del conjunto de los Estados-nación respecto a terceros (o lo que es lo mismo, define el escenario y la articulación de sus relaciones internacionales). Es, además, el contexto para 
la creación de la estructura jurídica, las instituciones y las reglas no escritas de la praxis política y de la autoridad ejercida por el aparato de Estado.

Además, no menos importante, la soberanía puede propiciar las mínimas condiciones para perfilar proyectos de nación; conciliar intereses variados, dispersos y hasta contradictorios; y definir las instituciones que delimitan expectativas, prescriben pautas de comportamiento y cursos de acción predecibles y le otorgan viabilidad y certidumbre a dichos proyectos (Keohane, 1993; Ayala Espino, 1999).

Si bien existen argumentos que esbozan la idea de que el Estado, ante la intensificación de los procesos de globalización, ya no es soberano en el sentido convencional de término (Scholte, 2005; Elkins, 1995), el meollo del problema de un Estado subdesarrollado como el mexicano radica en el hecho de que las decisiones públicas en él no se sujetan a una autonomía institucional, y que la ley no se hace valer para articular, sujetar y controlar a los poderes fácticos. De ahí que la autoridad política no se despliega de manera plena, y menos sobre los flujos transplanetarios y transfronterizos.

Sin embargo, esto no significa que la soberanía llegue a su ocaso, pues aunque los Estados no cuenten con las suficientes capacidades y recursos materiales para controlar todos los flujos - muchos de ellos también materiales- en todo momento y en todo lugar de su territorio, prevalece el ejercicio de esa soberanía como institución jurídica.

Los mecanismos de regulación y la autoridad política misma muestran una tendencia a la dispersión entre distintos agentes transestatales y transnacionales, pero esa cesión de soberanía compartida es resultado de la misma decisión autónoma de los Estados de transferir importantes porciones de sus potestades y capacidades de autonomía a esas redes globales de toma de decisiones. Al mismo tiempo, los propios Estados le brindan legitimidad a esa transferencia negociada, y tienden a ser complementados por los regímenes 
internacionales en sus esfuerzos reguladores de la vida social, sin que suela existir una contradicción u oposición entre sus regulaciones y las normas supranacionales provenientes de los espacios globales, cuanto más bien una articulación y sincronización para el perfeccionamiento de la necesaria institucionalidad global.

Sin embargo, en el escenario de relaciones económicas y políticas internacionales signadas por la estratificación y las asimetrías, una noción absoluta como la de soberanía, en tanto institución jurídica, no toma en cuenta la desigualdad social e internacional eslabonada en ese contexto contradictorio. Es precisamente en esos márgenes de desigualdad donde se agravan las insuficiencias y debilidades institucionales que condicionan las decisiones públicas y las posibilidades de proyectos autónomos de desarrollo.

A grandes rasgos, más que atemperar los fallos del mercado y dedicarse a la gestión directa del proceso económico, en este contexto el Estado orienta sus funciones y el sentido de su acción social a responder a la racionalidad propia de la economía global y a la renovada lógica de la acumulación de capital, esto con la finalidad de apuntalar las ventajas comparativas y competitivas de sus territorios privilegiados, brindar entornos institucionales a las inversiones allí establecidas y contribuir a la configuración de una institucionalidad global para eslabonar y consolidar espacios de flujos y espacios económicos transfronterizos. A ello se ajustan buena parte de las funciones y estrategias macroeconómicas, mesoeconómicas y microeconómicas del aparato de Estado en México.

Sin embargo, dado que sólo se presentarían en el contexto de un Estado fuerte y vigoroso institucionalmente, las posibilidades de eficiencia económica no se materializan en el mexicano. Más aún, el escenario se complica ante el hecho de que amplias franjas del territorio nacional, por acción, colusión u omisión, no son controladas por el aparato de 
El declive estructural de lo público y la dialéctica desarrollo/subdesarrollo: génesis y manifestaciones de la crisis de Estado en México

Estado al erigirse y consolidarse poderes y contrapoderes fácticos locales y globales que le disputan la hegemonía y tienden a configurar una parainstitucionalidad estatal.

\section{La crisis de lo público como manifestación de la transformación del Estado mexicano y de su autonomía en la toma de decisiones públicas}

La erosión de lo público en un Estado subdesarrollado como el mexicano encuentra su génesis y trasfondo en una crisis institucional que se remonta al sistema político autoritario y del presidencialismo fuerte, y se profundiza con la configuración difusa del poder y su dispersión en variados actores y agentes, así como con la pérdida de control sobre amplias porciones del territorio y las dificultades para ejercer el monopolio legítimo de la violencia.

Lo anterior tiene como correlato en la escala internacional, principalmente en Europa y los Estados Unidos, el rasgo ideológico dado por la entronización de las cosmovisiones posmodernas y las perspectivas ultraliberales y neoconservadoras que radicalizan el individualismo y privilegian lo privado por encima de lo público.

Además, a finales del siglo xx se generalizó la desconfianza en el Estado como la entidad capaz de emprender grandes transformaciones sociales, por no mencionar que la ley de hierro de la oligarquía (noción empleada por Robert Michels) y las maquinarias burocráticas propias del partido político (el príncipe moderno, en el lenguaje de Antonio Gramsci) se agotaron como mecanismos de mediación entre el aparato de Estado y las necesidades de las sociedades. A este panorama se suman también la ausencia de un lenguaje para hablar de la vida pública (Judt, 2010) o la ausencia de narrativas (Heins, 2016) para dar sentido al espacio público en el inédito contexto histórico de la post Guerra Fría y la globalización. Esto significa, siguiendo también a Judt 
(2010), que el lenguaje de la política se agotó y fue vaciado de sustancia y significado.

En el caso de México, más que un Estado fallido (Herman y Ratner, 1993; Rotberg, 2004) o la generalización de los rasgos de las zonas marrones (O’Donnell, 1993), lo que resulta posible interpretar es la emergencia de una crisis de Estado manifestada en una crisis institucional y en la fragmentación política del aparato de Estado tras ser sitiado por los poderes y contrapoderes fácticos y el generalizado desdén de la población y las autoridades respecto a lo público y la legalidad.

Dicho desdén se corresponde con la apropiación privada de lo común, de ahí que, a lo largo del siglo XX, el predominio de una fuerte y rígida tradición estatista mexicana sujeta por el control férreo, la centralización del poder político y el autoritarismo, marchó a la par de entramados institucionales gangrenados por la corrupción y la impunidad; las prácticas ilegales de múltiples funcionarios y ciudadanos; la preeminencia de las reglas no escritas sobre la legalidad instituida; la evasión fiscal y la dependencia respecto a la monoexportación de hidrocarburos; el patrimonialismo; la burocratización entorpecedora y depredadora; el usufructo privado de los bienes públicos; y la incapacidad para hacer valer el monopolio legítimo de la violencia. ${ }^{8}$ Todas estas prácticas se corresponden con una debilidad de la sociedad y de su cultura política, y con una participación ciudadana intermitente o regida por el régimen corporativo-clientelar que caracterizó al sistema político mexicano durante dicho siglo. Se trata de una vida pública postrada, o bien, a decir de algunos estudiosos, de una sociedad derrotada por la desidentidad y el desorden social, precipitados estos últimos con el cambio de modelo económico (Zermeño, 1996). 
En este contexto, desde el predominio del sistema político regido por el partido cuasioficial, la vida pública fue apropiada y cooptada por las élites políticas. Cuando menos hasta la década de los setenta, la información propia del proceso de toma de decisiones públicas y sus mecanismos fue controlada por dichas élites políticas, especialmente por la Presidencia de la república y el partido dominante (Cosío Villegas, 1972).

Este control se explica por las facultades constitucionales, metaconstitucionales e informales que reforzaron: 1) el control estatal sobre la gestión directa del proceso económico; 2) la centralización y concentración territorial del poder político y de las actividades económicas; 3) la cooptación y control de los movimientos sociales y demás grupos de presión; y 4) la subordinación de los Gobiernos locales y de los poderes Legislativo y Judicial.

Así, en el seno de una estructura de poder autoritaria y distante de la estructura jurídico-político-institucional formal, se gestó una ausencia de una democracia efectiva (González Casanova, 1975), y una sociedad carente de prácticas cívicas y débil cultura política no creó o permitió los contrapesos que, a lo sumo, se desplegaban en los márgenes, mecanismos y líneas del partido cuasioficial.

De esto se desprende que el espacio público no fuese autónomo, sino una entidad succionada y subsumida por el aparato de Estado, el partido hegemónico y sus prácticas corporativas y clientelares. Ese dislocamiento entre la estructura jurídica y la vida cotidiana de los individuos y organizaciones consolidó la transgresión del imperio de la ley pues hizo del deber ser una ficción nebulosa. Ese incumplimiento de la legalidad no sirvió para cuestionar y revertir una estructura social preñada por la desigualdad y la exclusión, sino que estos fenómenos fueron reproducidos y radicalizados. 
Al final del apartado anterior, se introdujo el concepto de parainstitucionalidad estatal para referir a una de las consecuencias de la crisis institucional experimentada en México, y para denotar aquel conjunto de comportamientos y prácticas informales que penetran la superficie y los sótanos de la sociedad.

Se trata de un fenómeno en el que organizaciones e instituciones convencionales con distinto grado de formalidad y presencia ${ }^{9}$ son vaciadas de legitimidad y suplantadas como mecanismos de socialización, convivencia y resguardo de la vida pública y de la integridad de los ciudadanos, lo que constituye entidades sociales parecidas a una serie de semiestados paralelos ${ }^{10}$ dotados de versatilidad, legitimidad, reconocimiento y base social que se enraízan en lo más profundo del imaginario social y le otorgan sentido a la cotidianidad de vastos segmentos de la población mexicana.

Este contra(poder) es ejercido por entidades sociales como las organizaciones del crimen organizado; los líderes gremiales que median entre el Estado y ciertos grupos sociales (como comerciantes ambulantes, asociaciones de transporte público que echan mano de la piratería en concesiones y permisos, colonos que invaden predios); las organizaciones de la teología de la prosperidad y demás Iglesias; los hospitales y las escuelas privadas que no cumplen con mínimos criterios de calidad y demás regulaciones; y las agencias de seguridad privada, entre otras.

Estas entidades tienden a erosionar y suplantar las funciones y alcances de las instituciones públicas, ahondando con ello el desdén y la desconfianza ciudadana respecto al espacio público, la ingobernabilidad y la desarticulación, dispersión y fragmentación político-institucional del apa-

9. Por ejemplo, la familia, la escuela, las Iglesias, las organizaciones comunitarias, las entidades recaudadoras de impuestos, las organizaciones para la procuración e impartición de justicia, la Policía, el Ejército, etc.

10. Esta noción ya ha sido introducida en Enríquez Pérez y Flores Sandoval (2017). 
rato de Estado, el cual no logra implantar su autoridad en la totalidad de un territorio cada vez más eclipsado por esos poderes fácticos que cuestionan su autoridad, legitimidad y hegemonía.

De este modo, el espacio público es subvertido a través de las enraizadas identidades y lealtades territoriales configuradas a partir de los convencionalismos y prácticas de individuos y grupos al margen de la ley, quienes consienten y legitiman prácticas ilegales que moldean su poder. Cabe destacar que estos (contra)poderes cuentan con capacidad para desplegar mecanismos de regulación y pautas de comportamiento entre individuos, grupos y comunidades.

Esta depredación de lo público adopta una relación dialéctica y recíproca con las transformaciones experimentadas en las funciones del Estado, y no es ajena al proceso de toma de decisiones propias de la agenda pública, especialmente cuando esta macroestructura institucional naufraga en una crisis sistémica.

\section{La dialéctica desarrollo/subdesarrollo y el torbellino de la crisis de Estado como desestructuración de los entramados institucionales}

¿Por qué son relevantes las instituciones y las dimensiones simbólico-culturales en los cauces que adopta la dialéctica desarrollo/subdesarrollo?, y ¿cómo incide la crisis institucional en ello? Un argumento es central para comprender el sentido de esta pregunta y sus manifestaciones en una sociedad subdesarrollada y socavada en su espacio público como la mexicana: ciertas culturas y formaciones sociales, particularmente aquellas donde se hace valer el derecho a la mayor igualdad y equidad económica y política, evidencian un considerable apego, aprecio, valoración y respeto por lo público. Ello redunda en la civilidad y el compromiso de sus ciudadanos y élites políticas, así como en un alto grado de 
formalización e institucionalización de ese compromiso, de tal forma que tienden a prevalecer una asimilación y un amplio sentido de lo público entre los ciudadanos.

A contracorriente de ello, en las territorialidades subdesarrolladas es débil o nulo ese respeto hacia lo público, a medida que prevalece un ejercicio de apropiación privada de lo público. En naciones como México, lo público históricamente se entremezcla con el prebendalismo, el patrimonialismo y el ejercicio depredador y faccioso del poder político, los cuales entronizan la apropiación y uso privados de la vida pública.

Entre el espacio público -y, en dado caso, su deterioro-y la emergencia y perpetuación del subdesarrollo, se suscita una relación orgánica y bidireccional, puesto que aquellas sociedades igualitarias que logran preservar el sentido de comunidad y la integridad de su vida pública y de sus entramados institucionales, así como un mayor e igualitario disfrute de servicios públicos como la educación, la salud y la seguridad social, se encuentran menos expuestas a la violencia y criminalización del tejido social, a la disolución y depredación del espacio público, y a la marginación y menosprecio de la cultura política.

Lo contrario ocurre en sociedades subdesarrolladas como la mexicana, regidas por la desigualdad social e internacional, puesto que ante la inequidad, la segregación social, la exclusión de la población en la toma de decisiones públicas y el generalizado desdén por la legalidad y el espacio público, las funciones e intervenciones del aparato de Estado son fragmentadas, desestructuradas, desarticuladas, débiles, inciertas, erráticas e, incluso, nulas respecto a la (re)distribución de la riqueza y la coordinación equilibrada entre la eficiencia económica y las posibilidades de equidad social, esto sin restar importancia al condicionamiento impuesto por la sujeción al mecanismo del mercado y al neoclientelismo político. 
Paralelamente a todo ello, los entramados institucionales débiles y socavados, así como la perpetuación de la desigualdad y exclusión sociales mismas, abonan el terreno para que las sociedades sean sitiadas por la violencia, la ilegalidad, la depredación del espacio público y la inhibición de la ciudadanía, mientras que el poder político, económico, territorial, simbólico, mediático que poseen los poderes fácticos tiende a concentrarse y a cuestionar los alcances y eficacia del Estado.

Precisamente en esto radica el sentido dialéctico y correlacionado de los fenómenos estudiados: en México, al ahondarse la crisis de la vida pública y de sus entramados institucionales, las sociedades se exponen a la perpetuación del subdesarrollo, en tanto que la reproducción y profundización de este fenómeno y de sus consecuencias entre los individuos y las comunidades erosiona el tejido social y agrava la crisis de Estado, al tiempo que demerita las facultades de este para articular y cohesionar a los frontales, difusos y dispersos poderes y contrapoderes fácticos.

De esta forma, la relación entre la dialéctica desarrollo/ subdesarrollo y la crisis de Estado se articula sistémicamente a medida que se genera un circuito entre distintos fenómenos convergentes entrelazados por su potencial para erosionar la función articuladora y cohesionadora del Estado mexicano.

Estos fenómenos disruptivos son:

1) La desigualdad social, sujeta también a las asimetrías propias de las relaciones económicas internacionales;

2) La incapacidad del sector público para definir un proyecto político de manera autónoma y con criterios nacionalistas;

3) El ejercicio deforme de la ciudadanía y la carente cultura política;

4) El desdén por lo público;

5) El círculo vicioso entre corrupción e impunidad; 
6) La generalización de la violencia, la ilegalidad y el bajo coste que supone infringir la ley a través del crimen; y

7) La crisis institucional.

Esta crisis de Estado se manifiesta a través de entramados institucionales sitiados, subvertidos, contrariados y cuestionados por los poderes y contrapoderes fácticos posicionados en los ámbitos estratégicos del sector público. Estos actores y organizaciones que hacen valer e imponer sus intereses facciosos, individuales y de grupo contribuyen a socavar y a vaciar de contenido a la praxis política y a las instituciones del Estado, al tiempo que desvirtúan las posibilidades de (re)construcción de un proyecto de nación que revierta las condiciones de subdesarrollo y sus contradicciones sociales.

En suma, la dimensión sociopolítica del subdesarrollo (Enríquez Pérez, 2016b) se manifiesta en México a través de esta desestructuración, depredación institucional y fragmentación político-territorial del Estado, que se agudiza con la influencia ejercida por las redes globales de toma de decisiones y su proceso de transnacionalización, estandarización, armonización, homogeneización y coordinación de políticas públicas sujetas a la racionalidad propia de la expansión e integración global del capitalismo.

Si el Estado mexicano fue sustraido de la gestión directa del proceso económico y transformado en sus funciones, su poder económico se desvaneció en lo operativo (no es más propietario de los medios de producción) y su poder político fue eclipsado con la remoción del régimen corporativo, que no era funcional al cambio en el patrón de acumulación.

$\mathrm{Al}$ perder vigencia este poder económico y político, y al agotarse el contrato social que le daba sentido al Estado desarrollista, los entramados institucionales mexicanos se tornaron frágiles y las potestades estatales dejaron de ser funcionales para el control político y la subordinación de los poderes y contrapoderes fácticos, la procuración de la 
El declive estructural de lo público y la dialéctica desarrollo/subdesarrollo: génesis y manifestaciones de la crisis de Estado en México

seguridad pública y la impartición de justicia, el ejercicio del monopolio legítimo de la violencia, y la gestación de decisiones públicas y estrategias de desarrollo con ciertos márgenes de autonomía.

\section{Conclusiones}

El advenimiento de la crisis de Estado en México tiene sus orígenes en la quiebra del régimen de economía mixta y el agotamiento del sistema político autoritario regido por el presidencialismo y el partido cuasioficial, dotado este de facultades y atribuciones constitucionales y metaconstitucionales que hicieron del espacio público un patrimonio de las élites políticas.

Con la erradicación de la noción de desarrollo del proyecto del nacionalismo revolucionario, y con la transición a un nuevo modelo económico que respondiera a las trasformaciones del emergente patrón de acumulación de la manufactura flexible, la sociedad mexicana se encaminó a la ruptura de los arreglos políticos e institucionales -formales e informales- entre los grupos, las clases sociales, las regiones y los poderes fácticos anteriormente controlados en sus intereses por los instrumentos autoritarios del sistema político.

Ahora son esos poderes y contrapoderes fácticos los que despuntan en la lucha orientada a penetrar y controlar el Estado en sus distintas escalas territoriales y de gobierno. La centralización en la toma de decisiones públicas y la concentración de riqueza y recursos financieros, mediáticos, simbólicos, violentos y territoriales en manos de estos poderes fácticos que se extralimitan son lo que explica, en parte, el ocaso de esos arreglos políticos y la crisis de Estado en el país.

Por si fuera poco, la crisis sistémica y de larga duración del capitalismo se combina con la crisis de sentido suscitada en las sociedades contemporáneas a raíz del miedo al 
futuro y la carente imaginación de las élites políticas y la academia para proyectar, desde el cultivo del pensamiento utópico, modelos alternativos de sociedad.

Lo anterior se relaciona también con la desconfianza de los individuos y las comunidades respecto a la ideología del liberalismo y respecto al Estado como arena para construir posibles soluciones de cara a las lacerantes problemáticas sociales y sus mecanismos de exclusión y desigualdad. Esta desconfianza en el Estado es expresión de un malestar en el Estado y con el Estado, que tiene como trasfondo un vaciamiento del sentido y significado de la política en tanto praxis para la transformación de la realidad social y para la emancipación de las sociedades. En esa vorágine también fluye, cual río caudaloso, la pérdida de legitimidad de la ideología del desarrollo y las dificultades suscitadas para su articulación y materialización desde la acción colectiva convocada por el Estado.

Finalmente, luego de interpretar la relación entre el declive de lo público, la crisis de Estado, el dislocamiento del poder respecto a la política, y la dinámica contradictoria, disruptiva y polarizante de la dialéctica desarrollo/subdesarrollo, cabe reflexionar en torno al sentido que adopta el proceso de toma de decisiones públicas y la planeación de cara a la intensificación de los procesos de globalización y el imperativo de la estandarización, armonización, homogeneización y coordinación de las políticas públicas, esto con miras a responder a la necesidad de crear entornos institucionales que apuntalen la expansión e integración global del capitalismo y los nuevos arreglos políticos que subyacen en las renovadas formas de (re)distribución de la riqueza.

Más aún, cabe ahondar en la reflexión respecto a la viabilidad y pertinencia del Estado mexicano ante estas tendencias contemporáneas y ante la proliferación y fortalecimiento de los poderes y contrapoderes fácticos que le 
disputan la hegemonía y la articulación y conducción de la vida social.

Cabe entonces preguntar: ¿Cómo comprender y enfrentar la fragmentación y crisis del Estado y de la vida pública en México? ¿Cómo reivindicar y (re)inventar el sentido y significado de la política? ¿De qué manera es posible contener, redefinir e incorporar los intereses de los poderes y contrapoderes fácticos en la eventual (re)construcción de un proyecto de nación en México? ¿Cómo aprovechar las fuerzas y factores exógenos que condicionan las decisiones públicas y el conjunto del proceso de planeación? ¿Cuáles son los mínimos criterios para (re)configurar la vida pública y (re)fundar al Estado mexicano? ¿Cómo articular la gravitación de fuerzas y factores exógenos y endógenos con las urgencias y necesidades locales/nacionales? ¿Cuáles serían los nuevos conceptos y categorías para estudiar la transformación del Estado y de sus funciones en el curso de la dialéctica desarrollo/subdesarrollo?

Brindar acercamientos y respuestas a estos interrogantes amerita confiar en la política como una praxis para la transformación y emancipación de la sociedad. También, requiere echar mano de la imaginación creadora y el pensamiento utópico para habilitar la participación de la acción colectiva en las decisiones públicas y en la defensa de lo público ante el avasallamiento del fundamentalismo de mercado y la entronización del individualismo a ultranza, que arroja a la humanidad al abismo de la crisis (des)civilizatoria.

Albrow, M. (1996). The global age. State and Society Beyond Bibliografía Modernity. Cambridge: Polity Press.

Altvater, E., y Mahnkopf, B. (1997). "The world market unbound". Review of international political economy, 3(4), 448-47I. 
Bibliografía

Altvater, E., y Mahnkopf, B. (2002). Las limitaciones de la globalización. Economía, ecología y política de la globalización. México: Siglo XXI y Centro de Investigaciones Interdisciplinarias en Ciencias y Humanidades de la UNAM.

Ayala Espino, J. (1999). Instituciones y economía. Una introducción al neoinstitucionalismo económico. México: Fondo de Cultura Económica.

Bauman, Z., y Bordoni, C. (20I6). Estado de crisis. Barcelona: Paidós.

Beck, U. (1998). La sociedad del riesgo. Hacia una nueva modernidad. Barcelona: Paidós.

Beck, U. (2002). La sociedad del riesgo global. Madrid:Siglo XXI. Camilleri, J. A., y Falk, J. (1992). The End of Sovereignty?:The politics of a shrinking and fragmenting world. Aldershot: Edward Elgar Pub.

Cosío Villegas, D. (1972). El sistema político mexicano. Las posibilidades de cambio. México: Joaquín Mortiz.

CosíoVillegas, D. (1974). El estilo personal de gobernar. México: Joaquín Mortiz.

Czempiel, E. O. (1989). "Internationalizing politics: some answers to the question of who does what to whom", en E. O. Czempiel, y J. N. Rosenau (eds.), Global change and theoretical changes. Approaches to world politics for the 1990s (pp. I I7-I35). Lexington: Lexington Books.

Drucker, P. F. (1994). La sociedad postcapitalista. Bogotá: Editorial Norma.

Elkins, D. J. (1995). Beyond sovereignty. Territorial and political economy in the twenty-first century. Toronto: University of Toronto Press.

Enríquez Pérez, I. (2016a). Las estrategias de desarrollo y los avatares de la planeación nacional:un estudio sociohistórico para la reconstrucción de un paradigma perdido en las políticas públicas mexicanas. Saarbrücken: Dictus.

Enríquez Pérez, I. (2016b). "El subdesarrollo como contradicción consustancial del capitalismo: notas introducto- 
rias para la (re)construcción de un concepto”. Estudios Bibliografía críticos del desarrollo, vI( I0), I3-48.

Enríquez Pérez, I., y Flores Sandoval, R. (20I7). “La crisis del espacio público y su incidencia en el subdesarrollo: incursiones en torno a la debilidad de las instituciones y del Estado en México". Discursos del sur. Revista de teoría crítica en ciencias sociales [en dictaminación].

Evans, P. (1995). Embedded autonomy. States and industrial transformation. Princeton: Princeton University Press.

González Casanova, P. (1975). La democracia en México. México: Era.

Guehénno, J. M. (1995). The end of the Nation state. Minneapolis: University of Minnesota Press.

Heins, V. M. (20I6). "Habermas on the European Crisis: Attempting the Impossible". Thesis Eleven. Critical Theory and Historical Sociology, I33(I), 3-18. doi: I0.1 I77/07255 I3616636378

Herman, G.,y Ratner, S. ( 1993). “Saving Failed States”. Foreing Policy, 89, 3-20.

lanni, O. (1996). Teorías de la globalización. México: Siglo XXI Y CEIICH/UNAM.

lanni, O. (1998). La sociedad global. México: Siglo XXI. lanni, O. (1999). La era del globalismo. México: Siglo XXI. Jessop, B. (2002). The future of the capitalist state. Cambridge: Polity Press.

Jessop, B. (2017). El Estado. Pasado, presente y futuro. Madrid: Libros de la Catarata.

Judt, T. (20I0). Algo va mal. Barcelona:Taurus.

Julius, D. (1997). "Globalization and Stakeholder Conflicts: A Corporate Perspective". International Affairs, 73(3), 453-468.

Kaul, I., Grunberg, I., y Stern, M.A. (eds.) (1999). Global public goods: International cooperation in the $2 I^{\text {st }}$ century. Nueva York: Oxford University Press. 
Bibliografía

Keohane, R. O. (1993). Instituciones internacionales y poder estatal. Ensayos sobre teoría de las relaciones internacionales.Argentina: Grupo Editor Latinoamericano.

López Villafañe, V. (I986). La formación del sistema político mexicano. México: Siglo XXI.

Messner, D. (1997). La globalización y el futuro de la política. Observaciones desde una perspectiva europea. México: Centro de Estudios de la Reforma del Estado y Fundación Friedrich Ebert Stiftung.

Naisbitt, J. (1994). The global paradox. Nueva York:William Morrow.

O’Donnell, G. (1993).“Acerca del Estado, la democratización y algunos problemas conceptuales: una perspectiva latinoamericana con referencias a países poscomunistas". Desarrollo económico, 33(130), I63-I84.

Ohmae, K. (1995). The end of the Nation state: the rise of regional economies. Nueva York: Simon and Schuster.

Paz, O. (1978). “El ogro filantrópico”. Vuelta, (2I), 38-44.

Paz, O. (1979). El ogro filantrópico: historia y política. México: Joaquín Mortiz.

Polanyi, K. (1992). La gran transformación. Los orígenes politicos y económicos de nuestro tiempo. México: Fondo de Cultura Económica.

Reinicke,W.H.(1999).“The OtherWorldWideWeb: Global Public Policy Networks”. Foreign Policy, (I I 7), 44-57.

Rotberg, R. I. (ed.) (2004). When States Fail: Causes and Consequences. Princeton: Princeton University Press.

Salas-Porras, A. (2014). "Las élites neoliberales en México: ¿cómo se construye un campo de poder que transforma las prácticas sociales de las élites políticas?". Revista mexicana de ciencias políticas y sociales, LIX(222), 279-3I 2.

Scholte,J.A. (1996)."Beyond the buzzword: towards a critical theory globalization”, en E. Kofman, y G.Youngs (eds.), Globalization: theory and practice (pp. 43-57). Londres: Pinter Pub Ltd. 
El declive estructural de lo público y la dialéctica desarrollo/subdesarrollo: génesis y manifestaciones de la crisis de Estado en México

Scholte,J.A. (2005). Globalization: a critical introduction. Nueva Bibliografía York: Palgrave Macmillan.

Strange, S. (1996). The retreat of the state. The diffusion of power in the world economy. Cambridge: Cambridge University Press.

Zermeño, S. (1996). La sociedad derrotada. El desorden mexicano de fin de siglo. México: Siglo XXI, Instituto de Investigaciones Sociales-UNAM. 